\title{
PREVALENCE OF MALOCCLUSION IN PRIMARY SCHOOLCHILDREN OF CAIRO, EGYPT (A SURVEY STUDY )
}

\author{
Mohummed Saif Soliman Fsifis*, Fatma Abdou Abd El-Sayed** and Hala Munir**
}

\begin{abstract}
This project was aimed to determine the prevalence of malocclusion among school children in Cairo governorates.

Materials and Methods: This study was carried out in Cairo governorate where a list of the primary schools and the number of primary school children in Cairo governorate were obtained from the database of the Ministry of Education. Cairo governorate was divided into four regions according to geographical location, two and sometimes three schools were chosen randomly from each region using SAS computer software thus, 20 schools were included in this study and a total number of 1936 schoolchildren were included in this survey.
\end{abstract}

Results: Distribution of Angle classification: this study showed that 497 children (25.7\%) had accepted occlusion while, 997 children had Angle Class I malocclusion representing (51.5\%) of the study sample, 318 children had Angle Class II malocclusion representing (16.4\%) of the study sample while 115 children had Class III malocclusion representing (5.9\%) of the study sample and 9 children had Class IV representing $(0.5 \%)$ of the study sample. Overjet: The most frequent category was normal overjet $(>0-3.5 \mathrm{~mm})$ which was found to be $(71.8 \%)$. Anterior open bite $(<0 \mathrm{~mm})$ was found in $(5.9 \%)$ of the total sample.

Conclusion: Compared to previous Egyptian studies, there was a tendency toward decrease in the prevalence of accepted occlusion while, there was an increase in Angle Class II and III malocclusion.

\section{INTRODUCTION}

The term malocclusion encompasses all deviations of teeth and jaws from normal alignment and relations including discrepancies between teeth and jaw size, malposition of individual teeth and malrelationship of the dental arches in sagittal, transverse and vertical dimensions ${ }^{1}$. The etiology of malocclusion may be due to genetic factors, environmental factors or more commonly a combination of both inherited and environmental factors acting together such as adverse oral habits,

* B.D.S Cairo University, Master Degree of Orthodontics, Cairo University

** Professor of Orthodontics, Faculty of Oral and Dental Medicine, Cairo University 
anomalies in number, form and developmental position of teeth can cause malocclusion ${ }^{2}$.

Malocclusion has a large impact on the individual and the society in terms of discomfort, quality of life, social and functional limitations such as: impaired esthetics, speech impairment, interference with normal growth and development, abnormal muscle function, promotion to dental caries, predilection to periodontal disease, tempromandibular joint disorders and unfavorable psychological disorders ${ }^{3}$.

The recognition of these disorders in dentistry implies the need for planning preventive, interceptive and corrective orthodontic measures to provide adequate treatment. For such planning it is essential to carry out epidemiological studies of malocclusion prevalence and to assess the treatment need for such disorders, so that early recognition of developing malocclusions and the potential for uncomplicated orthodontic treatment procedures can minimize or eliminate future costly treatment ${ }^{4}$.

Furthermore, the growing demand for orthodontic treatment necessitates the development of a variety of clinically based indices that classify various types of malocclusion, and determine their priority in orthodontic treatment need. ecently, orthodontic treatment need has been expressed by a series of indices including the Dental Aesthetic Index, the Treatment Priority Index, the Index of Complexity Outcome and Need, and the Index of Orthodontic Treatment Need (IOTN) ${ }^{5}$.

Brook and Shaw have introduced the IOTN that based on a dental health component (DHC) and an aesthetic component which when compared to previous methods, the IOTN is said to be objective, synthetic, and allows for comparisons between different populations groups. The widespread use of the IOTN in epidemiological studies could be useful for comparing the treatment need in different populations and is suitable for planning community dental health resources ${ }^{6}$.
This project aimed to determine the prevalence of malocclusion and orthodontic treatment need among school children in Cairo governorates.

\section{MATERIALS AND METHODS}

Thist study was carried out in Cairo governorate where a list of the primary schools and the number of primary school children in Cairo governorate were obtained from the database of the Ministry of Education. The total number of primary school students was 636201 enrolled in 1132 schools. Cairo governorate was divided into four regions according to geographical location, two and sometimes three schools were chosen randomly from each region using SAS computer software thus, 20 schools were included in this study.

\section{Sample type :}

It is a stratified two-stage cluster sample proportionate to the size of the community.

\section{Sample size calculation:}

According to Daniel ${ }^{7}$ Power analysis was performed to determine the minimum required sample size. Sample size was calculated based on standard marginal error of $0.01 \%$ and a $95 \%$ confidence interval.

One hundred randomly selected students from each school in which four or five schools were chosen randomly from each four regions that represent Cairo. The randomly-chosen students were examined and those who did not meet the inclusion criteria were excluded from the sample a sample of $\mathbf{1 9 3 6}$ students was included in this study.

\section{Inclusion criteria}

1- School children of both genders born to Egyptian parents.

2- Children having an age range from 8-12 years. 


\section{Exclusion criteria}

1- Craniofacial anomalies that affect jaw relation and dentition except cleft lip and palate.

2- History of facial trauma or surgery.

3- Systemic diseases that affect craniofacial growth.

4- Previously orthodontically treated students.

\section{Methods:}

\section{1- Clinical Examination:}

The health care specialist in each school assisted the examiner in bringing in the children from classes for screening at the school clinic. Each student was seated on an ordinary chair with the head in an upright position under good illumination. The child was instructed to occlude on his posterior teeth to assess anteroposterior, vertical and transverse dental relations using latex gloves, mouth mirrors and plastic rulers. Each child was then asked to open his/her mouth for intra arch dental assessment. Intra-arch examination included; displacement (crowding), missed teeth, supernumerary teeth, submerged (ankylosed) teeth, impeded eruption of teeth and clefts of lip and/or palate. No radiographs or study casts were used.

\section{1-Assessment of Molar Relation (Angle Classification):}

\section{Accepted occlusion:}

The occlusion was categorized as accepted occlusion if molar relationship was Angle Class I normal occlusion (mesiobuccal cusp of the upper first permanent molar occluded in the anterior buccal groove of the lower first permanent molar), average overbite $1-4 \mathrm{~mm}$, average overjet ( $>0$ to $3.5 \mathrm{~mm}$ ) \& proper dental alignment.

\section{Angle Class I malocclusion:}

The mesiobuccal cusp of the maxillary first permanent molar occluded with the buccal groove of the mandibular first molar, where the teeth were approximated in centric occlusion. But local abnormalities were seen such as; rotations, spacing, crowding, open or deep bite and increased or reversed overjet.

\section{Angle Class II Malocclusion:}

The occlusion was classified as Angle Class II malocclusion when the lower first permanent molar was positioned distally more than one half unit $(>3$ $\mathrm{mm})$ relative to the upper first permanent molar (postnormal occlusion)

\section{Angle Class III malocclusion:}

The occlusion was classified as Angle Class III when the lower first permanent molar was mesially positioned more than half unit $(>3 \mathrm{~mm})$ relative to the upper first permanent molar (pre-normal occlusion)

\section{Angle Class IV malocclusion:}

The occlusion was classified as Class IV where the maxillary and mandibular first permanent molar presented Class II relation on one side while the first molar on the contralateral side presented Class III molar relationship.

\section{2-Overjet $(\mathrm{OJ})$ :}

Overjet is the horizontal distance between the incisal edge of the upper central incisor and the labial surface of the lower central incisor, it was measured to the nearest $0.5 \mathrm{~mm}$ in millimeters using a plastic ruler ${ }^{8}$.

\section{Reverse Overjet:}

When all upper incisors were in crossbite, reverse overjet was measured in millimeters using a plastic ruler to the nearest $0.5 \mathrm{~mm}$

\section{3 - Overbite (OB) (Vertical Overlap):}

Overbite is the perpendicular distance from the edge of the lower central incisor to the upper central incisor edge on occlusion which was measured in millimeters ${ }^{8}$. 
The upper incisor vertical overlap was marked using a pencil as a horizontal line drawn on the lower incisor then each child was asked to open his/ her mouth to measure the distance from the incisal edge of the marked tooth using a plastic ruler to the horizontal line.

\section{Open Bite:}

An anterior open bite was recorded when there was no vertical overlap of the incisors on occlusion, where the shortest vertical distance was measured using a plastic ruler. The same was done for posterior open bite.

\section{Statistical analysis}

Qualitative data were presented as frequencies and percentages. Chi-square (x2) test was used for comparisons related to qualitative data. Numerical data were presented as mean, standard deviation (SD), minimum and maximum values. Data were explored for normality by checking the data distribution, calculating the mean and median values. The program that was used is SPSS. The Pvalue for statistical significance was set at 0.05 .

\section{RESULTS}

This study was conducted on 1936 randomly selected children 8-12 years of age from Cairo governorate; 948 males (49\%) and 988 females (51\%), (Table 2, Fig. 1) with a mean age of 10.5 \pm 1.0 years. The sample included 1137 children (58.7\%) aged 8-10.5 years old which represented the early mixed dentition group while, 799 children (41.3\%)aged 10.6-12 years old represented the late mixed dentition group

Distribution of Angle classification: this study showed that 497 children (25.7\%) had accepted occlusion while, 997 children had Angle Class I malocclusion representing (51.5\%) of the study sample, 318 children had Angle Class II malocclusion representing (16.4\%) of the study sample while 115 children had Class III malocclusion representing (5.9\%) of the study sample and 9 children had Class IV representing $(0.5 \%)$ of the study sample.

Overjet: The most frequent category was normal overjet $(>0-3.5 \mathrm{~mm})$ which was found to be $(71.8 \%)$, of the total sample, moderate overjet $(>3.5-6 \mathrm{~mm})$ was (17.9\%), increased overjet ( $>6-9 \mathrm{~mm})(4.7 \%)$, edge to edge $(0 \mathrm{~mm})$ was $(3.8 \%)$, reverse overjet $(<0$ $\mathrm{mm}$ ) was $(1.2 \%)$, while the least frequent category was severe overjet $(>9 \mathrm{~mm})$ which recorded $(0.5 \%)$ of the study sample.

Overbite: Normal overbite (1-4 mm) represented (74.1\%) of the study sample, moderate overbite (4-6 $\mathrm{mm}$ ) represented $(13.2 \%)$ of the study sample while, severe over bite $(>6 \mathrm{~mm})$ was found in $(6.5 \%)$. Anterior open bite $(<0 \mathrm{~mm})$ was found in $(5.9 \%)$ of the total sample while, the least frequent category was edge to edge $(<0 \mathrm{~mm})$ which was seen in $(3 \%)$ of the sample.

\section{DISCUSSION}

Malocclusion represented (74.3\%) of the total sample of which (51.5\%) were Angle Class I, (16.4\%) Angle Class II, (5.9\%) Angle Class III and (0.5\%) Angle Class IV. The prevalence of accepted occlusion was found to be (25.7\%) which was found to be less than a previous Egyptian study $(27.5 \%)$ by Abdel Kader ${ }^{9}$ The difference which could be due to a change in socioeconomic conditions in Egypt. In addition, it was found to be lower than British (67.3\%) and it was higher than those of Libyians (3\%), Iranians (4\%) and Chinese $(7.1 \%)$ as shown by Gardiner ${ }^{10}$, ${ }^{11}$ and Lew et $a{ }^{12}$ Europe, and America, it would be useful for dental practitioners to be informed about malocclusion prevalence among Chinese. This study was carried out on 1050 Chinese school children (aged 12-14 years respectively.

On the other hand, the prevalence of malocclusion (74.3\%) was lower than that of an Israeli population (95.9\%) as performed by Krzpow et $\mathrm{al}^{13}$. this difference which could be due to different ethnic and environmental conditions. 
The prevalence of Angle Class I malocclusion $(51.5 \%)$ in the present study was found to be lower to a previous Egyptian study (65.1\%) performed by Abdel Kader ${ }^{9}$ and lower than that of Mexican adolescents $(72.8 \%)$ as studied by Pruneda et al ${ }^{14}$ after calibration of examiners $(\mathrm{Cr}=88 \%, \mathrm{Ca}=$ $90 \%, \mathrm{~K}=0.89$., but higher than that of Belgians (31\%) and Nigerians (50.0\%) as shown by Willems et $\mathrm{al}^{15}$ and Onyeaso ${ }^{16}$ respectively. The prevalence of Angle Class II malocclusion was (16.4\%) in the current study which was found to be higher than that of a similar previous Egyptian study (4.7\%) performed by Abdel Kader ${ }^{9}$ and that of Tanzanian (3\%) and Kenyan populations (7.9\%) which was recorded by Kerosuo et al ${ }^{17}$ age $11-18$ yr, Garner and Butt $^{18}$ respectively. However, it was lower than that of a Croatian study $(45.1 \%)$ by Lauc ${ }^{19}$ and a Turkish study (44.7\%) by Gelgör et $\mathrm{al}^{20}$.

On the other hand, the prevalence of Angle Class III malocclusion in the present study was (5.9\%) which was found to be higher than that of Abdel Kader's ${ }^{9}$ study on Egyptian children (2.7\%) due to environmental changes, also higher than those of Saudi Arabians (3\%) Jordanians (1.4\%) and Israelis (2.6\%) as shown in previous studies by Al-Emran et $\mathrm{al}^{21}$, Abu Alhaija et $\mathrm{al}^{22} 1002$ students randomly selected to represent five geographical areas of Irbid were examined. The examinations were carried out twice, first on the pupils in the school premises and then using study models taken from each student. The dental health (DHC, and Krzpow et $\mathrm{al}^{23}$ respectively. Additionally, it was lower than that found in a Chinese (19.9\%) population as studied by Tang $^{24}$, and Garner and Butt ${ }^{18}$ on a Kenyan (16.8\%) population. The prevalence of Angle Class IV in the present study $(0.5 \%)$ was found to be lesser than that of a previous Egyptian study (0.8\%) reported by El-Mangoury and Mostafa ${ }^{25}$.

The prevalence of acceptable overjet was found to be $(71.8 \%)$, which was comparable to that of a German (60.2\%), Croatian (69.6\%) and a Nigerian population $(69.6 \%)$ by Tausche et $\mathrm{al}^{26}$ possibly because there is little scientific evidence that such interventions are of actual benefit. The aim of this study was to determine specific factors for treatment need in the early mixed dentition period in order to obtain basic data to support early intervention. The study was part of a larger survey of 8768 children aged between 6 and 17 years. From this sample, 1975 children aged between 6 and 8 years were used to estimate the prevalence of malocclusions using the Index of Orthodontic Treatment Need (IOTN, Lau ${ }^{19}$ cand Onyeaso ${ }^{16}$ respectively. Increased maxillary overjet of $\geq 6 \mathrm{~mm}$ was seen in $(4.7 \%)$ of the sample which was close to the findings of a Kuwaiti Arab sample of (7.8\%) as reported by Behbehani et $\mathrm{al}^{27}$. However, the prevalence of increased overjet $(4.7 \%)$ in the present study was lower than that of Saudi Arabian school children (18.4\%) as reported by AlEmran et $\mathrm{al}^{21}$, Jordanians (22\%) and Turkish children $(25.1 \%)$ as reported by Hamdan ${ }^{28}$ while grade 3 represented 'borderline need' and grades 2 and 1 'no need' for treatment. In\nRESULTS: A 'definite need' for treatment was recorded in $28 \%$ of children and $22 \%$ had 'border line' need on dental health grounds. Three main occlusal features were responsible for allocating children into the former category; severe displacements of more than $4 \mathrm{~mm}$ (45\% and Gelgör et $\mathrm{a}^{20}$ respectively.

Reverse overjet was found in $(1.2 \%)$ of the sample which was lower than to that reported by Al-Emran et $\mathrm{al}^{21}$ on Saudi Arabian school children (3.2\%), Kuwaiti adolescents (4\%) and Iranian children (4.2\%) as recorded by Behbehani et $\mathrm{al}^{27}$ and Borzabadi-Farahani et $\mathrm{al}^{29}$ respectively.

However, Tang ${ }^{24}$ reported a prevalence of $(15.4 \%)$ of reverse overjet in Chinese children which was higher than that found in this study. These differences indicated that the Chinese have a tendency to have a deficient maxilla more than the Caucasian's face. 
The prevalence of moderate deep overbite was found to be $(17.9 \%)$ in the present study which appeared to be higher than that of Saudi Arabian school children (3.6\%) as reported by Al-Emran et $\mathrm{al}^{21}$. This difference might be due to the different defining methods of deep overbite where the Saudi Arabian study defined deep bite when it was more than $5 \mathrm{~mm}$ but the current study considered deep bite when it was more than $4 \mathrm{~mm}$. The prevalence of severe overjet was $(0.5 \%)$ in this study.

The prevalence of open bite in present study was $(5.9 \%)$ which was higher than that of a Swedish population $(3.7 \%)$ by Ingervall et $\mathrm{al}^{30}$ the awareness of malocclusion, the demand for orthodontic treatment and the prevalence of malocclusion were studied in 389 Swedish men, aged 21-54 years (mean age 32 years, Icelanders $(2.5 \%)$ by Jonsson et $\mathrm{al}^{31} 342$ men and 487 women, aged 31 to 44 years, who completed questionnaires about their orthodontic treatment experiences and were available for clinical examination. Results: Complete dentitions in both jaws were present in $52.8 \%$ of the women and $45.3 \%$ of the men at the examinations. Significantly higher percentages of the women had received orthodontic treatment of some kind $(24.3 \%$ compared with $16.9 \%$ for the men, and Croatians $(3.1 \%)$ by Lauc $^{19}$, however, it was lower than that of a British population $(8.4 \%)$ as reported by Lavelle et $\mathrm{al}^{32}$.

\section{CONCLUSION}

1- In Cairo, school children with accepted occlusion represented $\mathbf{2 5 . 7 \%}$ of the total sample while, malocclusion represented $\mathbf{7 4 . 3 \%}$ of the total sample of which $\mathbf{5 1 . 5 \%}$ showed Angle Class I, 16.4\% showed Angle Class II, 5.9\% showed Angle Class III, while $\mathbf{0 . 5 \%}$ showed Angle Class IV.

2- Compared to previous Egyptian studies, there was a tendency toward decrease in the prevalence of accepted occlusion while, there was an increase in Angle Class II and III malocclusion.

\section{REFERENCES}

1. Samir Bishara. Textbook of Orthodontics.Saunders Publisher.; 2001.

2. Leighton BC. Aetiology of malocclusion of the teeth. Arch. Dis. Child. 1991;66(9):1011-1012.

3. Bollen a M. Effects of malocclusions and orthodontics on periodontal health: evidence from a systematic review. J Dent Educ 2008;72(8):912-918.

4. Karaiskos N, Wiltshire W a., Odlum O, Brothwell D, Hassard TH. Preventive and interceptive orthodontic treatment needs of an Inner-City Group of 6- and 9-year-old Canadian children. J. Can. Dent. Assoc. (Tor). 2005;71(9).

5. Borzabadi-Farahani A. An Overview of Selected Orthodontic Treatment Need Indices 1. Princ. Contemp. Orthod. 2011;12(2):215-236.

6. Brook, PH; Shaw W. The development of an index of orthodontic treatment priority. Eur. J. Orthod. 1989;20:309-320.

7. Wayne Daniel. Biostatistics: A Foundation for Analysis in the Health Science.Ninth Edition. Laurie Rosatone Publishing. Pages: 956.; 2008.

8. Moyers R. Handbook of orthodontics. In: Handbook of Orthodontics. 3rd Ed. Year book medical publisher.; 1973:148-68.

9. Abdel Kader W. The prevalence of malocclusion in a group of Egyptian Children. Master thesis, Cairo Univ. 1980.

10. Gardiner JH. An orthodontic survey of Libyan schoolchildren. Br. J. Orthod. 1982;9(1):59-61.

11. Atashi M. Prevalence of Malocclusion in 13-15 Year-old Adolescents in Tabriz. Res. Dent. Clin. Dent. Prospect. 2007;1(1):13-18.

12. Lew KK, Foong WC, Loh E. Malocclusion prevalence in an ethnic Chinese population. Aust. Dent. J. 1993; 38(6):442-449.

13. Krzpow AB, Lieberman MA, Modan M. Prevalence of malocclusion in young adults of various ethnic backgrounds in Israel. J. Dent. Res. 54(3):605-8.

14. Murrieta Pruneda Francisco José, Alejandra CDP, Jasiel LA, Violet. Dental Malocclusion: Prevalence in a group of Mexican adolescents and their relationship to age and gender. Rev. Fac. Odontol. Univ. Antioquia 2007;45(1).

15. Willems G, De Bruyne I, Verdonck a, Fieuws S, Carels C. Prevalence of dentofacial characteristics in a belgian orthodontic population. Clin. Oral Investig. 2001;5(4):220-226. 
16. Onyeaso, Chukwudi Ochi. Prevalence of malocclusion among adolescents in Ibadan, Nigeria. Am. J. Orthod. Dentofac. Orthop. 2004;126:604-607.

17. Kerosuo H, Laine T, Kerosuo E, Ngassapa D, Honkala E. Occlusion among a group of Tanzanian urban schoolchildren. Community Dent. Oral Epidemiol. 1988;16:306-309.

18. Garner LD, Butt MH. Malocclusion in black Americans and Nyeri Kenyans. An epidemiologic study. Angle Orthod. 1985;55(2):139-146.

19. Lauc T, Schäfer K, Prossinger H, Slaj M. Orofacial analysis on the Adriatic Islands: 1. The island of Hvar as a model for odontogenetic researches. Coll. Antropol. 2000;24 Suppl 1:63-69.

20. Gelgör IE, Karaman AI, Ercan E. Prevalence of malocclusion among adolescents in central anatolia. Eur. J. Dent. 2007; (July):125-131.

21. Al-Emran S, Wisth PJ, Böe OE. Prevalence of malocclusion and need for orthodontic treatment in Saudi Arabia. Community Dent. Oral Epidemiol. 1990;18(Table 1):253-255.

22. Abu Alhaija ESJ, Al-Nimri KS, Al-Khateeb SN. Orthodontic treatment need and demand in 12-14-year-old north Jordanian school children. Eur. J. Orthod. 2004;26(3):261-263.

23. Krzpow a B, Lieberman M a, Modan M. Prevalence of malocclusion in young adults of various ethnic backgrounds in Israel. J. Dent. Res. 1975;54(3):605-608.
24. Tang EL. The prevalence of malocclusion amongst Hong Kong male dental students. Br. J. Orthod. 1994; 21(1):57-63.

25. El-Mangoury NH, Mostafa YA. Epidemiologic panorama of dental occlusion. Angle Orthod. 1990;60:207-214.

26. Tausche E, Luck O, Harzer W. Prevalence of malocclusions in the early mixed dentition and orthodontic treatment need. Eur. J. Orthod. 2004;26(3):237-244.

27. Behbehani F, Årtun J, Al-Jame B, Kerosuo H. Prevalence and severity of malocclusion in adolescent Kuwaitis. Med. Princ. Pract. 2005; 14:390-395.

28. Hamdan AM. Orthodontic treatment need in Jordanian school children. Community Dent. Health 2001;18(3):177-80.

29. Borzabadi-Farahani A, Borzabadi-Farahani A, Eslamipour F. Malocclusion and occlusal traits in an urban Iranian population. An epidemiological study of 11- to 14-yearold children. Eur. J. Orthod. 2009;31(5):477-484.

30. Ingervall B, Mohlin B, Thilander B. Prevalence and awareness of malocclusion in Swedish men. Community Dent. Oral Epidemiol. 1978;6(18):308-314.

31. Jonsson T, Arnlaugsson S, Karlsson KO, Ragnarsson B, Arnarson EO, Magnusson TE. Orthodontic treatment experience and prevalence of malocclusion traits in an Icelandic adult population. Am. J. Orthod. Dentofac. Orthop. 2007;131:11-18.

32. Lavelle CLB. A study of multiracial malocclusions. Community Dent. Oral Epidemiol. 1976;4(1):38-41. 